\title{
Impaired Extinction Retention in Adolescent Rats: Effects of D-Cycloserine
}

\author{
Jessica McCallum', Jee Hyun Kim ${ }^{1,2}$ and Rick Richardson*,1 \\ 'School of Psychology, University of New South Wales, Anzac Parade, Kensington, New South Wales, Australia
}

\begin{abstract}
The developmental trajectory of the prefrontal cortex (PFC) in both rats and humans is nonlinear, with a notable decline in synaptic density during adolescence, potentially creating a 'natural lesion' preparation at this age. Given that the PFC is critically involved in retention of extinction of learned fear in adult humans and rodents, the present study examined whether adolescent rats exhibit impaired extinction retention. The results of experiment I showed that adolescent rats were impaired in extinction retention, compared with both younger and older rats. The partial NMDA receptor agonist D-cycloserine (DCS) improved extinction retention in adolescent rats (experiment 2), but only if administered immediately after extinction training (experiment 3). In addition, providing extended extinction training improved extinction retention in adolescent rats in a manner similar to that of DCS (experiment 4). The results of this study show that adolescent rats exhibit impaired extinction retention, and that this can be reduced through either DCS or extended extinction training. These novel findings have potential implications for clinical treatments of fear and anxiety disorders in adolescent patients.

Neuropsychopharmacology (2010) 35, 2134-2142; doi:I0.1038/npp.2010.92; published online 30 June 2010
\end{abstract}

Keywords: learned fear; extinction; adolescence; rats; spontaneous recovery; relapse

Just as animals can learn to fear a stimulus that predicts an aversive outcome, they can also learn to inhibit this learned fear. The most common way to inhibit fear is through the process of extinction, in which the feared stimulus is repeatedly presented without its associated aversive outcome. Extinction is widely accepted as the basis for exposure-based therapies (Myers and Davis, 2002), and preclinical studies of extinction have led to a number of advances in the treatment of anxiety disorders (Hofmann, 2007).

Recent preclinical research has shown fundamental developmental differences in extinction of learned fear (Kim and Richardson, 2010). Specifically, a number of typical extinction-related phenomena do not occur in the preweanling rat. For example, postnatal day 16 rats do not

This research was submitted by the first author as part of her Honours thesis for a Bachelors of Psychology degree at The University of New South Wales, and was supported by a Discovery grant from the Australian Research Council (DP0985554) to RR.

*Correspondence: Dr R Richardson, School of Psychology, University of New South Wales, Anzac Parade, Kensington, New South Wales 2052, Australia, Tel: + 6 I 029385 I048, Fax: + 6 I 029385 364I, E-mail: R.RICHARDSON@UNSW.EDU.AU

${ }^{2}$ Current address: Department of Psychology, University of Michigan, 530 Church Street, Ann Arbor, MI 48109-1043, USA.

Received 26 February 2010; revised 31 May 20I0; accepted 31 May 2010 exhibit either reinstatement (Kim and Richardson, 2007a) or renewal of extinguished fear (Kim and Richardson, 2007b; Yap and Richardson, 2007). In addition, the medial prefrontal cortex (PFC) is not involved in extinction of learned fear in preweanling rats (Kim et al, 2009), but is critically involved in postweaning and adult rats (Herry and Garcia, 2003; Kim et al, 2009). Further, NMDA is not involved in extinction in preweanling rats (Langton et al, 2007), but is in postweaning and adult rats (Baker and Azorlosa, 1996; Langton et al, 2007; Langton and Richardson, 2008).

Another developmental period of particular interest with regard to the extinction of fear is adolescence. In humans, adolescence is often characterized by higher instability and emotional intensity compared with adults (Larson et al, 1980). In addition, recent histological and MRI studies have shown that the brain is subjected to considerable restructuring during adolescence (Choudhury et al, 2006). Specifically, the volume of PFC declines during adolescence in humans (Sowell et al, 1999), and a similar result has been reported in rats (Van Eden et al, 1990). This decline in volume is due to a 'reorganization' of synaptic connections (Blakemore and Choudhury, 1999), with an estimated loss of $50 \%$ of neocortical synapses within the PFC during adolescence (Huttenlocher, 1984; Mrzljak et al, 1990). This substantial decrease in PFC volume could have a significant impact on the extinction of 
fear. Lesions of PFC in rats affect neither the expression of learned fear nor the within-session rate of extinction (Lebron et al, 2004). However, lesioned rats have impaired memory of extinction when tested the following day; that is, their fear returns more than that observed in controls (Quirk et al, 2000). Further, depression of PFC synaptic efficacy has no effect on either acquisition of fear or within-session extinction (ie, the decrease in fear across the repeated presentations of the fear-eliciting stimulus), but it does impair extinction retention (Herry and Garcia, 2003). In humans, extinction retention is positively correlated with PFC thickness (Milad et al, 2005). Taken together with several fMRI studies that examined extinction retention in humans (Milad et al, 2007; Phelps et al, 2004), these studies provide strong evidence suggesting that an active PFC is critical for successful extinction retention. As mentioned earlier, the developmental trajectory of PFC in both rats and humans is largely nonlinear (Geidd, 2004; Gogtay et al, 2004; Shaw et al, 2008), with a decline in volume during adolescence. Considering this, it would seem likely that adolescents would have impaired extinction retention; ie, their fear should be more likely to recover over time. Given that many anxiety disorders emerge during adolescence (Kessler et al, 2005), an understanding of potential developmental differences in the extinction of fear during this age could provide invaluable insight into the treatment of such disorders during this stage of development.

To date, there has been little experimental analysis of fear extinction in the adolescent animal. In one relevant study, it was reported that adolescent mice exhibited more rapid fear conditioning compared with adult mice, but no age differences were found for extinction (Hefner and Holmes, 2007). However, that study only examined within-session extinction. As noted above, lesions of PFC do not impair within-session extinction. Rather, functional integrity of the PFC seems to be more important for extinction retention. Therefore, in this study, we examined whether the adolescent rat exhibits impaired extinction retention relative to younger and older rats.

\section{MATERIALS AND METHODS}

\section{Subjects}

Experimentally naive male Sprague-Dawley rats obtained from the breeding colony maintained by the School of Psychology at the University of New South Wales were used. Rats were weaned at postnatal day $21 \pm 1$, and placed in plastic boxes $(67 \times 40 \times 22 \mathrm{~cm})$ in groups of eight. They were maintained on a $12 \mathrm{~h}$ light-dark cycle (lights on at 0700) with food and water available ad libitum. All procedures were approved by the local Animal Care and Ethics Committee and followed the guidelines of Australian Code of Practice for the Care and Use of Animals for Scientific Purposes (2004, 7th Edition). In experiment 1, rats were 24,35 , or 70 days of age (preadolescent, adolescent, and adult rats, respectively) at the time of fear extinction. In experiments 2-4, all rats were 35 days of age at the time of fear extinction.

\section{Apparatus}

Conditioning chamber. Fear conditioning occurred in a rectangular chamber $(20 \times 12 \times 12 \mathrm{~cm})$ that was housed inside a wood cabinet to reduce external noise and visual stimulation. The ceiling, front and back wall of the chamber were made of clear perspex, with the floor and side walls consisting of $3 \mathrm{~mm}$ stainless steel bars set $13 \mathrm{~mm}$ apart. Ventilation fans within the chamber produced a low level of background noise, and illumination was provided by white LEDs. Two speakers through which an auditory CS could be presented were attached $8 \mathrm{~cm}$ from either side of the chamber. An infrared camera was attached to the rear wall of the cabinet and allowed the animal's behavior to be recorded.

Extinction/test chamber. Extinction/test occurred in a chamber $(30 \times 30 \times 35 \mathrm{~cm})$ constructed of clear perspex with the exception of the grid floor $(3 \mathrm{~mm}$ stainless steel rods set $1 \mathrm{~cm}$ apart). This chamber was housed inside a wood cabinet to reduce external noise and visual stimulation; a ventilation fan produced a low level of constant background noise, and illumination was provided by white LEDs. Two speakers through which an auditory CS could be presented were attached to the top of the chamber. An infrared camera was attached to the rear wall of the cabinet and allowed the animal's behavior to be recorded.

Stimuli. The CS was a white noise, $8 \mathrm{~dB}$ above background. A custom-built constant current generator was used to present a $0.6 \mathrm{~mA}, 1 \mathrm{~s}$ shock US to the floor of the conditioning chamber. The presentations of the CS and US were computer controlled and the software was custom developed at the University of New South Wales.

\section{Drugs}

In experiments 2-4, rats were injected with either D-cycloserine (DCS; Sigma-Aldrich, Castle Hill, New South Wales) or saline. DCS was freshly dissolved in $0.9 \%$ sterile saline. All injections were given subcutaneously in the nape of the neck at a volume of $1.0 \mathrm{ml} / \mathrm{kg}$.

\section{Procedure}

Handling and context preexposure. All rats were handled for 3-4 min each day for 2 consecutive days; after the rats were handled, on each day, they were placed in the conditioning chamber for $\sim 10 \mathrm{~min}$ (context preexposure).

Fear conditioning. Rats were placed in the conditioning chamber and, after a 2-min adaption period, three white noise CS presentations were given. Each CS lasted $10 \mathrm{~s}$ and the shock US was administered in the last second. The intertrial interval ranged from 85 to $135 \mathrm{~s}$ with a mean of $110 \mathrm{~s}$.

Extinction training. Approximately $24 \mathrm{~h}$ after conditioning, rats were placed in the extinction/test chamber and allowed a 2-min adaption period. In experiments 1-3, all rats were then given $30 \mathrm{CS}$ presentations (10 s each) in the absence of the US; the intertrial interval was $10 \mathrm{~s}$. In experiment 4, two groups were given $30 \mathrm{CS}$ presentations and one group was given $60 \mathrm{CS}$ presentations in the absence of the US. 
Drug injection. In experiment 2, rats were injected with either saline or a low $(5 \mathrm{mg} / \mathrm{kg})$ or high $(15 \mathrm{mg} . \mathrm{kg})$ dose of DCS within $10 \mathrm{~min}$ of the last extinction trial. In experiment 3 , rats were injected with saline or $15 \mathrm{mg} / \mathrm{kg}$ of DCS either within $10 \mathrm{~min}$ after the last extinction trial or $4 \mathrm{~h}$ later. In experiment 4, some rats were injected with either saline or $15 \mathrm{mg} / \mathrm{kg}$ of DCS within $10 \mathrm{~min}$ of the last extinction trial.

Test. Approximately $24 \mathrm{~h}$ after extinction, rats were placed in the extinction/test chamber and allowed a 1-min adaption period. The CS was then presented for $2 \mathrm{~min}$. The conditioning, extinction, and test procedures are those that we have used in previous developmental studies on extinction of learned fear (eg, Kim and Richardson, 2007a, b).

Scoring. Freezing was taken as the measure of learned fear, and was defined as the absence of all movement except that needed for respiration (Fanselow, 1980). A time-sampling procedure was used, in which a rat was determined to be 'freezing' or 'not freezing' every $3 \mathrm{~s}$; the percentage of total observations scored as freezing was then determined for each rat. A second observer, unaware of the rat's experimental condition, scored a random sample of $30 \%$ of the test data. Interrater reliability was high in each experiment $(r s>0.94)$. The percentage of recovered fear was calculated by taking each animal's score at test and dividing it by its score at the first block of extinction. The average of each group was then calculated.

Exclusion criteria. To ensure that the animals had learned and remembered the CS-US association, they were required to exhibit some threshold level of freezing at the beginning of extinction training. Any rat that had a mean freezing level $<30 \%$ during the first block of extinction was excluded from all analyses. Further, any rats that were statistical outliers at test (performance more than 2.5 SDs away from the group mean) were excluded. In all, 15 out of 139 rats failed to acquire the CS-US association and two were statistical outliers. Of the 15 rats that failed to meet the learning criterion, 8 came from experiment 1 (3 from the 24-day-old group, 4 from the 35-day-old group, and 1 from the 70 day-old group), 2 came from experiment 2 ( 1 from the low DCS group, 1 from the high DCS group), 3 came from experiment 3 ( 1 from each group), and 2 came from experiment 4 (1 from the saline group and 1 from the DCS group).

\section{RESULTS}

\section{Experiment 1}

Experiment 1 examined whether there were differences in extinction retention between preadolescent, adolescent, and adult rats $(24,35$, and 70 days of age, respectively; ns at each age was 12,13 , and 15 , respectively). The timeline for this experiment is shown in Figure 1a. As noted earlier, there is evidence that the PFC undergoes substantial changes during adolescence (Van Eden et al, 1990), and that the PFC is critical for extinction retention (Herry and Garcia, 2003; Quirk et al, 2000; Milad et al, 2005). Thus, if the decreases in PFC volume during adolescence are akin to a 'natural lesion', then adolescent rats should exhibit impaired extinction retention relative to the other age groups.

Conditioning. Figure $1 \mathrm{~b}$ shows the mean freezing scores for each CS presentation, and, as can be seen, conditioning was successful. Statistical analysis (In all four experiments, conditioning and extinction data were analyzed using a mixed model design with trial as a repeated measure and condition/age as a between-group factor. In cases in which sphericity was violated, a Greenhouse-Geisser correction was made in the reported $p$ values, but the nominal degrees of freedom are reported in the text.) confirmed that there was a significant effect of trial, with freezing increasing across trials, $F(2,60)=42.22, p<0.001$. The effect of age, and the trial-by-age interaction, was not significant $(F s<1)$.

Extinction. There were no differences in pre-CS freezing across age, $\mathrm{F}(2,30)=1.68, p>0.1$; see Table 1 . Freezing during the $30 \mathrm{CS}$ presentations was collapsed into five blocks (six presentations per block) and is shown in Figure 1c. Extinction was successful in that all groups showed high levels of freezing during the first block, which decreased substantially by the last block, $\mathrm{F}(4,120)=22.86$,
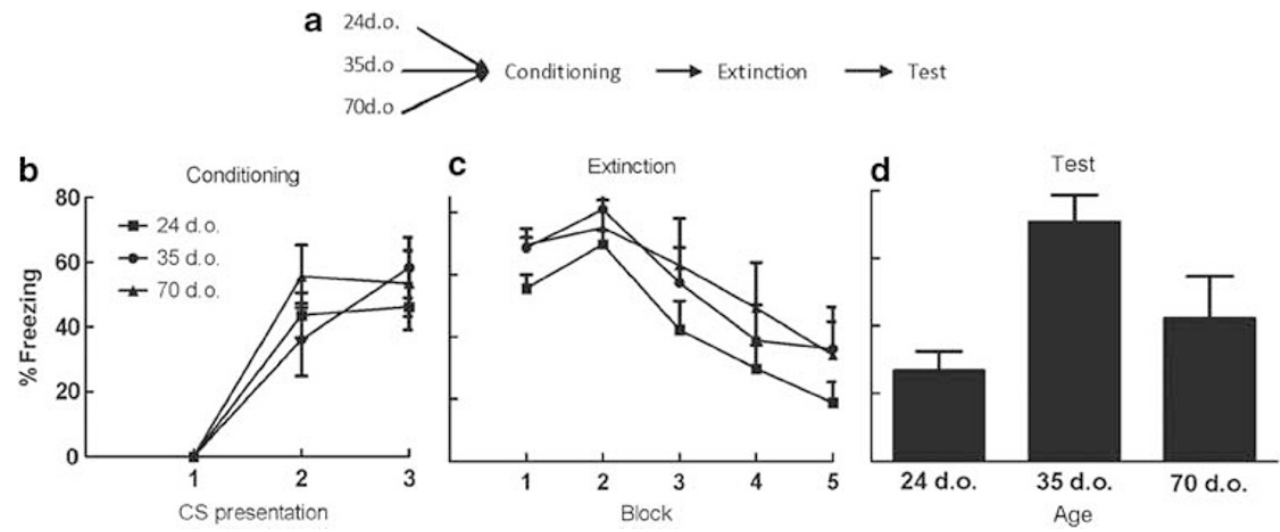

Figure I (a) The training protocol for experiment I, with each arrow indicating I day. Mean ( \pm SEM) percentage of CS-elicited freezing is shown for each group at training (b), extinction (c), and test (d) in experiment I. Rats (35 days old) show impaired extinction retention (ie, higher levels of freezing) at test compared with 24- and 70-day-old rats. 
Table I Mean $( \pm$ SEM) Percentage of Pre-CS Freezing at Extinction and Test Across all Four Experiments

\begin{tabular}{llrr}
\hline Experiment & Group & Extinction & Test \\
\hline 1 & P24 & $3.65 \pm 1.85$ & $0.76 \pm 0.8$ \\
& P35 & $12.70 \pm 4.53$ & $13.33 \pm 6.75$ \\
& P70 & $6.16 \pm 5.95$ & $5 \pm 3.64$ \\
& & & \\
& P35-saline & $15.9 \pm 7.27$ & $8.84 \pm 5.89$ \\
& P35-low DCS & $18.26 \pm 7.68$ & $7.69 \pm 5.38$ \\
& P35-high DCS & $11.25 \pm 6.64$ & $5.0 \pm 2.17$ \\
& & & \\
& P35-imm DCS & $2.5 \pm 1.87$ & $10.41 \pm 5.87$ \\
& P35-del DCS & $12.77 \pm 6.83$ & $12.77 \pm 10.97$ \\
& P35-saline & $25.83 \pm 9.95$ & $26.1 \pm 8.47$ \\
& & & \\
4 & P35-DCS & $1.07 \pm 0.89$ & $1.81 \pm 1.46$ \\
& P35-saline & $0.93 \pm 0.70$ & $6.87 \pm 4.39$ \\
& P35-extra extinction & $8.0 \pm 3.42$ & $0.5 \pm 0.52$ \\
\hline
\end{tabular}

Abbreviation: DCS, D-cycloserine.

$p<0.001$. The effect of age, and the age-by-block interaction, was not significant $(F s<1)$.

Test. There were no differences in pre-CS freezing levels across age, $\mathrm{F}(2,37)=1.53, p>0.1$; see Table 1 . In contrast, there were significant differences in CS-elicited freezing across age (Figure 1d), F $(2,37)=7.62, p<0.05$. Pairwise comparisons, using Tukey's honestly significant differences (HSD) test, revealed that 35-day-old rats had significantly higher levels of CS-elicited freezing than did 24-day-old rats $(p<0.01)$ or 70 -day-old rats $(p<0.05)$. The latter two groups did not differ $(p>0.1)$. These results show that 35-day-old rats exhibit impaired extinction retention. In terms of percentage recovery, ie, level of freezing at test compared with that seen in the first block of extinction, adolescent rats exhibited complete recovery, (105\% recovered fear), whereas the other groups exhibited more modest and comparable levels of fear recovery ( $45 \%$ recovery for the 24-day-old rats and 57\% recovery for the 70-day-old rats). Further, these differences cannot be attributed to age differences in either acquisition of fear (Figure 1b) or within-session extinction of fear (Figure 1c), as both of these were very similar across the three age groups (also see Kim et al, in press).

\section{Experiment 2}

This experiment examined whether extinction retention could be improved in adolescent rats. Previous research has shown that DCS, an NMDA receptor partial agonist, facilitates extinction retention in adult rats (Ledgerwood et al, 2003; Walker et al, 2002). Furthermore, DCS has also been observed to reduce relapse effects, such as reinstatement (Bertotto et al, 2006; Ledgerwood et al, 2004; but see Bouton et al, 2008). Therefore, in this experiment, adolescent rats were injected with 0,5 , or $15 \mathrm{mg} / \mathrm{kg}$ of DCS within $10 \mathrm{~min}$ of the last extinction trial (ns $=13,13$, and 14, respectively); see Figure $2 \mathrm{a}$ for a timeline.

Conditioning. As can be seen in Figure 2b, conditioning was successful. Statistical analysis confirmed that there was a significant effect of trial, with levels of freezing increasing across trials, $\mathrm{F}(2,66)=52.49, p<0.001$. The effect of group, and the group-by-trial interaction, was not significant, $(F s<1)$.

Extinction. The groups did not differ in levels of pre-CS freezing, $\mathrm{F}<1$; see Table 1. As shown in Figure 2c, all groups exhibited high levels of CS-elicited freezing in the first block of extinction, which decreased substantially by the last block. Analysis of variance revealed a significant effect of block, F $(4,132)=46.49, p<0.001$. The effect of group, and the group-by-block interaction, was not significant $(F s<1)$.

Test. The groups did not differ in levels of pre-CS freezing, $\mathrm{F}<1.0$; see Table 1 . In contrast, there were significant group differences in levels of CS-elicited freezing, $\mathrm{F}(2,37)=4.16$, $p<0.05$; see Figure 2d. Pairwise comparisons, using Tukey's HSD test, revealed that rats in the saline condition had significantly higher levels of CS-elicited freezing than did rats given the high dose of DCS $(p<0.05)$. The rats given the low dose of DCS did not differ from rats given saline $(p>0.1)$ or from those given the high dose of DCS $(p>0.05)$. As in experiment 1 , adolescent rats exhibited a pronounced return of fear when tested $24 \mathrm{~h}$ after extinction training (90\% recovered fear). However, this poor retention of extinction was attenuated if rats were injected with $15 \mathrm{mg} / \mathrm{kg}$ of DCS immediately after extinction (64\% recovery). A lower dose of DCS $(5 \mathrm{mg} / \mathrm{kg})$ was ineffective (95\% recovery).

\section{Experiment 3}

This experiment examined whether DCS has to be given soon after extinction to enhance extinction retention in adolescent rats. Previous research suggests that DCS functions to enhance consolidation of the new learning that occurs during extinction (see Davis et al, 2006, for review). For example, a previous study in adult rats showed that DCS failed to facilitate extinction retention when given $4 \mathrm{~h}$ after extinction training (Ledgerwood et al, 2003). Therefore, in this experiment, three groups of 35-day-old rats were fear conditioned, and then extinguished on the following day. One group was injected with saline either $10 \mathrm{~min}$ after the last extinction trial $(n=5)$ or $4 \mathrm{~h}$ later $(n=4)$; these two groups were collapsed into a single 'saline' control group. A second group $(n=12)$ was injected with $15 \mathrm{mg} / \mathrm{kg}$ of DCS within $10 \mathrm{~min}$ after the last extinction trial. Rats in a third group $(n=9)$ were injected with $15 \mathrm{mg} /$ $\mathrm{kg}$ of DCS $4 \mathrm{~h}$ after the last extinction trial (see Figure $3 \mathrm{a}$ ). It was expected that the immediate DCS would enhance extinction retention, but the delayed DCS would not.

Conditioning. As can be seen in Figure 3b, conditioning was successful. Statistical analysis confirmed that there was a significant effect of trial, with levels of freezing increasing across trials, $\mathrm{F}(2,54)=70.39, p<0.001$. The effect of group, 


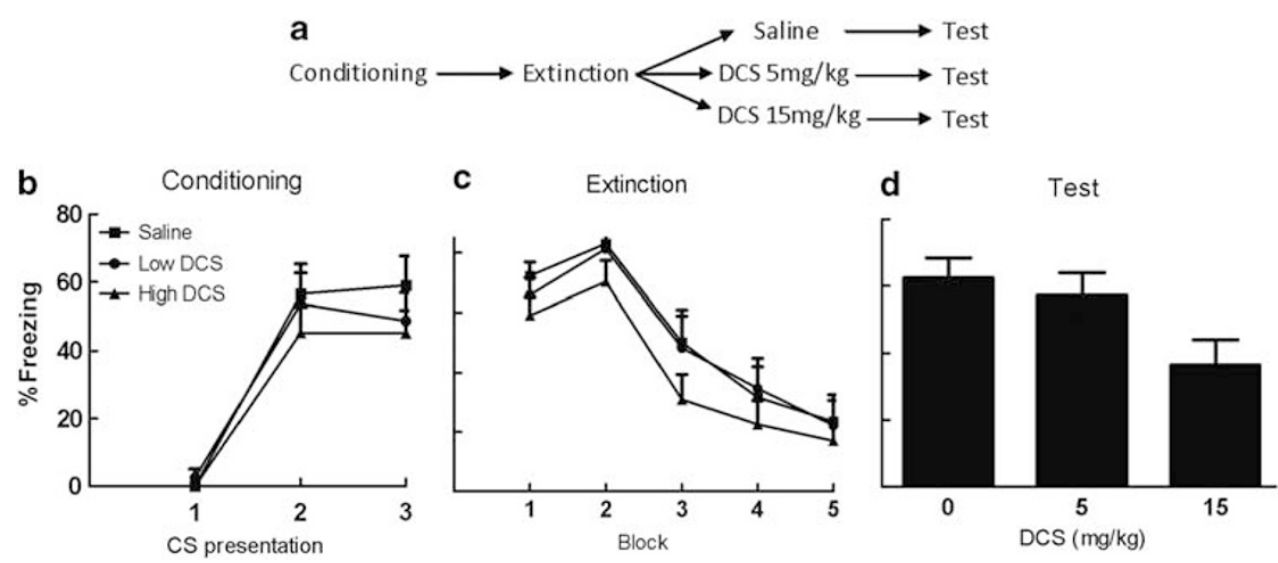

Figure 2 (a) The training protocol for experiment 2, with each arrow indicating I day, with the exception of the interval between extinction and injection, which was 10 minutes. Mean ( \pm SEM) percentage of CS-elicited freezing is shown for each group at training (b), extinction (c), and test (d) in experiment 2. A high dose of DCS resulted in significantly less freezing at test compared with saline in adolescent rats.

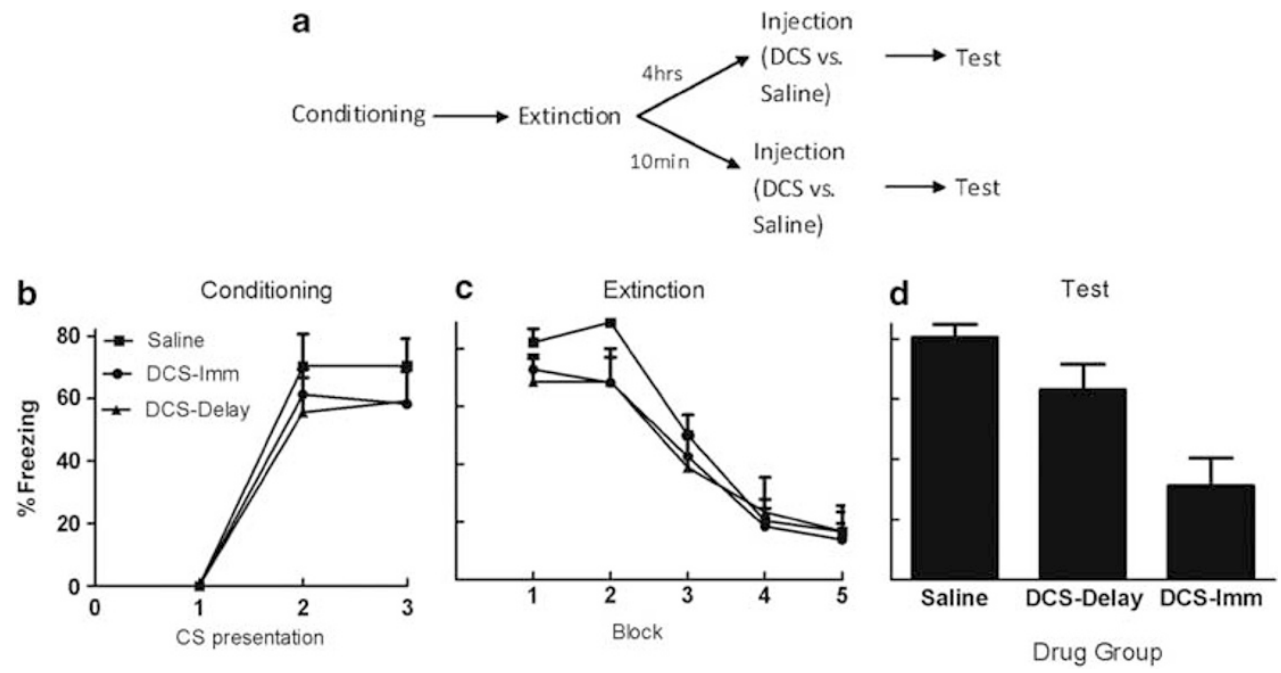

Figure 3 (a) The training protocol for experiment 3, with each arrow indicating I day, unless otherwise indicated. Mean ( \pm SEM) percentage of CS-elicited freezing is shown for each group at training (b), extinction (c), and test (d) in experiment 3. Immediate injection of DCS resulted in significantly less freezing at test compared with the saline control group in adolescent rats. However, a $4 \mathrm{~h}$ delayed injection of DCS resulted in no difference compared with the saline control group.

and the group-by-trial interaction, was not significant, $(F s<1)$.

Extinction. Analysis of pre-CS freezing levels revealed a significant group difference, $F(2,27)=3.87, p<0.05$, because of the rats in the saline condition having higher baseline freezing levels than rats in the DCS-immediate condition (see Table 1). Because of these differences, extinction data were analyzed by analysis of covariance with pre-CS freezing as the covariant. As shown in Figure 3c, all groups exhibited high levels of CS-elicited freezing in the first block and substantially less freezing by the last block, $F(4,104)=48.44, p<0.001$. The effect of group, and the group-by-block interaction, was not significant $(F s<1)$.

Test. There were no group differences in pre-CS freezing levels, $\mathrm{F}(2,27)=1.11, p>0.1$; see Table 1 . In contrast, there were significant group differences in CS-elicited freezing,
$\mathrm{F}(2,27)=10.34, p<0.001$; Figure 3d. Pairwise comparisons, using Tukey's HSD test, revealed that adolescent rats given DCS immediately after extinction had lower levels of freezing than did adolescent rats given saline immediately after extinction $(p<0.001)$ or rats given DCS $4 \mathrm{~h}$ after extinction $(p<0.05)$; these latter two groups did not differ $(p>0.1)$. As in the previous two experiments, 35-day-old rats exhibited very poor retention of extinction when tested $24 \mathrm{~h}$ later. Those rats given saline had $100 \%$ recovered fear, whereas those given DCS had substantially less fear recovery ( $43 \%$ recovery). Injecting DCS $4 \mathrm{~h}$ after extinction did not reduced the amount of fear recovery at test the following day (105\% recovery).

\section{Experiment 4}

In this experiment, we examined the effect of giving additional extinction trials on extinction retention in adolescent rats. In past research with adult rats it has been 

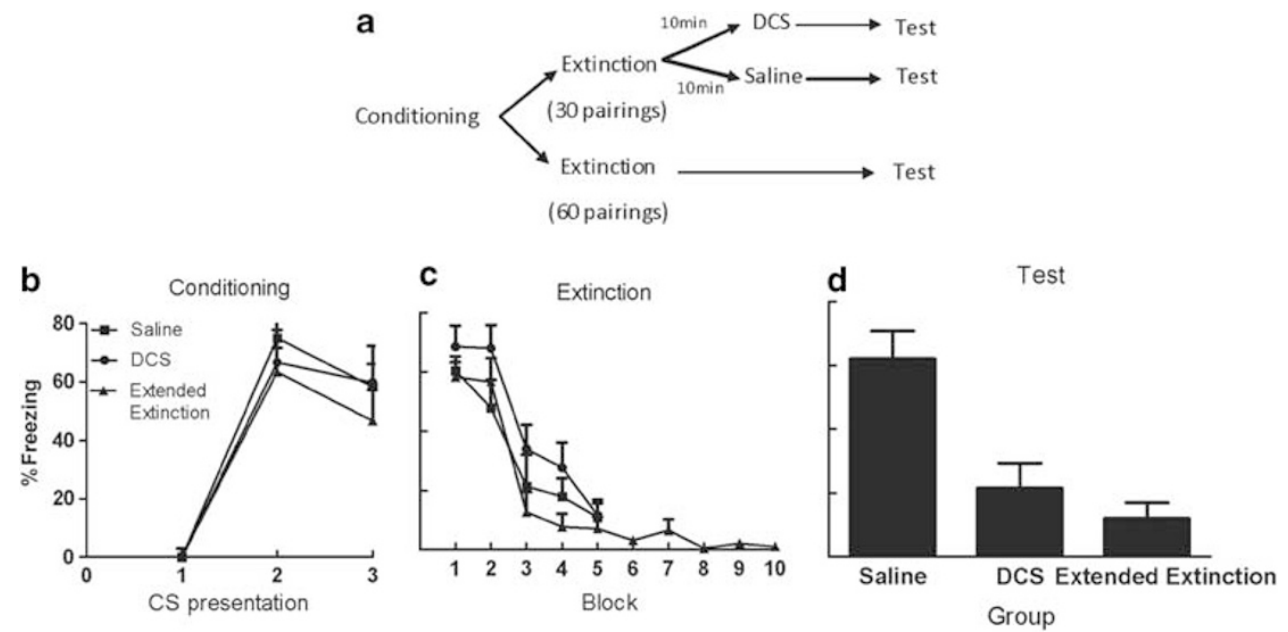

Figure 4 (a) The training protocol for experiment 4, with each arrow indicating I day, unless otherwise indicated. Mean ( \pm SEM) percentage of CS-elicited freezing is shown for each group at training (b), extinction (c), and test (d) in experiment 4. Adolescent rats in the saline control group exhibited significantly higher levels of freezing at test compared with rats given DCS after extinction, and rats given no injection but double the extinction training. There were no differences between the DCS and extended extinction groups.

shown that doubling the number of extinction trials leads to a comparable improvement in extinction retention as does administering DCS (Ledgerwood et al, 2005). Further, it has also been shown that adult rats with lesions of the PFC can exhibit some retention of extinction if they are given additional extinction training (Lebron et al, 2004). Therefore, in the present experiment, three groups of adolescent rats were fear conditioned. On the following day, two groups were extinguished as in the previous experiments; rats in one of these groups were injected with saline within 10 min after extinction $(n=8)$ and rats in the other group were injected with $15 \mathrm{mg} / \mathrm{kg}$ DCS $(n=11)$. Rats in the third group were given double the amount of extinction (ie, 60 extinction trials rather than 30$)$ and not injected $(n=10)$; see Figure $4 \mathrm{a}$ for a timeline.

Conditioning. As can be seen in Figure $4 \mathrm{~b}$, conditioning was successful. Statistical analysis confirmed that there was a significant effect of trial, with levels of freezing increasing across trials, $\mathrm{F}(2,56)=51.69, p<0.001$. The effect of group, and the group-by-trial interaction, was not significant, $(F s<1)$.

Extinction. There were no group differences in pre-CS levels of freezing, $\mathrm{F}(2,26)=2.15, p>0.1$; see Table 1 . All groups showed high levels of CS-elicited freezing in the first block and substantially less freezing by the fifth block, F $(4,104)=63.42, p<0.001$; see Figure $4 c$. The effect of group, and the group-by-block interaction, was not significant, $F s<1$.

Test. There were no group differences in pre-CS levels of freezing, $\mathrm{F}(2,26)=2.15, p>0.1$; see Table 1 . In contrast, there was a significant group difference in CS-elicited freezing, $F(2,26)=12.21, p<0.001$; Figure 4d. Pairwise comparisons, with Tukey's HSD test, revealed that rats given saline had higher levels of CS-elicited freezing than rats given DCS $(p<0.01)$ or rats given double the amount of extinction training $(p<0.001)$; the latter two groups did not differ $(p>0.1)$. Once again, 35-day-old rats exhibited very poor retention of extinction when tested $24 \mathrm{~h}$ later. Those rats given saline after the extinction session exhibited complete recovery of fear at test the following day $(106 \%$ recovered fear). Those rats given either DCS immediately after extinction or given double the number of extinction trials exhibited markedly less recovery of fear at test the following day (31 and 23\% recovery, respectively).

\section{DISCUSSION}

We hypothesized that adolescent rats would show poorer extinction retention (ie, greater fear relapse) when tested $24 \mathrm{~h}$ after extinction training compared with both younger and adult rats. This hypothesis was based on evidence that PFC (1) is critical for extinction retention (Herry and Garcia, 2003; Quirk et al, 2000; Milad and Quirk, 2002), and (2) undergoes substantial restructuring during adolescence (Blakemore and Choudhury, 1999), to the point that it might even be seen as a 'natural lesion'. Experiment 1 confirmed this hypothesis, with adolescent rats exhibiting significantly higher levels of freezing at test compared with both younger (ie, preadolescent) and older (ie, young adult) rats (also see Kim et al, in press). Experiment 2 then showed that this impairment in extinction retention in adolescent rats could be alleviated by injecting $15 \mathrm{mg} / \mathrm{kg}$ of DCS immediately after the extinction session; a lower dose of DCS $(5 \mathrm{mg} / \mathrm{kg})$ was ineffective. Experiment 3 replicated the finding that DCS enhances extinction retention in the adolescent rat, and also showed that it had to be given shortly after the extinction session to be effective; ie, injecting DCS $4 \mathrm{~h}$ after extinction had no effect. Finally, experiment 4 replicated the DCS finding once again, and also showed that doubling the amount of extinction training led to a similar improvement in extinction retention in the adolescent rat.

The results of experiments 1-4 consistently show that adolescent rats fail to retain an extinction memory over a 24-h period. Across the four experiments, adolescent rats 
exhibited a comparable and essentially complete recovery of fear at test the following day (ie, 105, 90, 100, and $106 \%$ recovery of fear, as compared with the first block of extinction trials, in experiments 1-4, respectively). It is important to note that the present results also show two ways in which the impaired extinction retention in adolescent rats can be alleviated. First, systemic injection of the NMDA receptor partial agonist DCS immediately after the extinction session led to enhanced retention (ie, lower levels of freezing; experiments 2-4). This result could be because of one of several mechanisms. One possible mechanism for the observed effect of DCS on retention of extinction in adolescent rats is that it enhanced the activity of NMDA receptors in the PFC. In a recent study, we examined phosphorylated MAPK (pMAPK) in the PFC of 24,35 , and 70 day olds, using the same procedures as in this study. We measured pMAPK in that study because previous research had shown that extinction involves activation of the mitogen-activated protein kinase/extracellular signalregulated kinase (MAPK/ERK) signaling pathway in the mPFC (Kim et al, 2009), and that postextinction blockade of MAPK/ERK in the mPFC disrupts long-term extinction (Hugues et al, 2004, 2006). In our recent study, levels of pMAPK in the PFC $1 \mathrm{~h}$ after extinction training was elevated in 24- and 70-day-old rats, but not in 35-day-old rats (Kim et al, in press). This finding suggests that PFC is not activated in the adolescent rat when the current training/ extinction procedures are used. This could be the reason why the adolescent rat exhibits such poor extinction retention. Injecting DCS immediately after extinction may lead to an increased level of PMAPK in the PFC of adolescent rats, which then leads to enhanced retention of extinction. Some support for this notion is provided by a recent study, in which infusion of the NMDA antagonist CPP directly in the PFC impaired fear extinction retention in adult rats (Burgos-Robles et al, 2007). In addition, a recent fMRI study found that administration of DCS enhanced PFC activity during symptom provocation in spider phobics (Aupperle et al, 2009). Another possible mechanism for the observed enhancing effects of DCS on extinction retention in adolescent rats is that the DCS enhances activity of NMDA receptors in the amygdala, leading to a stronger extinction memory. It is well established that the amygdala has a high density of NMDA receptors (Monaghan and Cotman, 1985), and numerous studies have shown the importance of these particular receptors in extinction retention by directly infusing either NMDA receptor antagonists (Falls et al, 1992) or the partial receptor agonist DCS (Ledgerwood et al, 2003; Walker et al, 2002) into the amygdala.

A second way in which the impaired extinction retention in adolescent rats can be alleviated is by doubling the number of extinction trials from 30 to 60 . Adolescent rats treated in this way showed comparable low levels of freezing (ie, good retention of extinction), as did adolescent rats given DCS immediately after 30 extinction trials (experiment 4). This finding is similar to the finding that adult rats with lesions of the PFC can eventually exhibit retention of extinction if given extra extinction training (Lebron et al, 2004), and the finding that doubling the number of extinction trials in adult rats leads to a comparable improvement in extinction retention as does injecting
DCS (Ledgerwood et al, 2005). It will be interesting to determine whether the mechanism mediating this improvement in extinction retention is the same, or different, to that mediating the improvement produced by DCS.

The findings from the present study showing that adolescent rats show markedly poorer retention of extinction, compared with both younger and older rats, may mean that treatment gains made in adolescents are much more vulnerable to relapse. Importantly, the results reported here also suggest that the poor retention of extinction in adolescent rats can be completely overcome by either doubling the amount of extinction training or by injecting the NMDA receptor partial agonist DCS immediately after extinction. Although some clinical research has failed to find a benefit of administering DCS (Storch et al, 2007), several other studies have found that DCS enhances treatment outcomes in adults suffering from various anxiety disorders (Guastella et al, 2008; Hofmann et al, 2006; Ressler et al, 2004; Wilhelm et al, 2008; see Norberg et al, 2008, for meta-analysis). The results of this study, if they can be extended to humans, suggest that DCS might be an effective pharmacological adjunct to exposure-based therapy in adolescent populations as well.

\section{Future Research Directions}

In all four experiments in this study, adolescent rats (ie, 35 days of age) exhibited poor retention of extinction over a 24-h interval. That is, despite showing low levels of fear at the end of the extinction training session (see panel (c) in all four figures), these rats exhibited substantially higher levels of freezing at test the next day (also see Kim et al, in press). This effect was not observed in either younger (ie, 24 days of age) or older (ie, 70 days of age) rats (experiment 1; also Kim et al, in press). We did not test to determine the exact age that this impaired extinction retention first emerges or when it no longer occurs, but other research has shown that activity in the infralimbic PFC is critically involved in extinction retention in rats aged 24-30 days (Santini et al, 2008). On the basis of that finding, one would predict that impaired extinction retention first emerges sometime after 30 days of age. However, determination of the exact time when this impairment first occurs will have to await future studies, as will the determination of the exact age at which the impairment is no longer observed.

In addition, future experiments are needed to determine the location in the brain where DCS is having its effects. As noted earlier, the enhancement of extinction retention in adolescent rats given DCS could be because of its action in either the PFC or the amygdala (or both). In the present study, DCS was given systemically, so conclusions about the neural bases of the observed effects are not possible. On the basis of our hypothesis that the impaired extinction retention observed in adolescent rats is due to the restructuring of the PFC during this period of development, we predict that infusions of DCS into the PFC will enhance extinction retention in adolescent rats. In the present study, we also found that doubling the number of extinction trials enhanced extinction retention in adolescent rats. Future experiments will be needed to determine whether this manipulation affects extinction retention through the same mechanism(s) as does DCS. For example, do both 
treatments affect activity in the PFC and therefore lead to enhanced extinction retention? In that regard, we have found that doubling the number of extinction trials does lead to increased number of pMAPK immunoreactive cells in the infralimbic cortex of adolescent rats (Kim et al, in press). We do not currently know whether administering DCS immediately after extinction will have a similar effect.

It will also be important to examine whether DCS, or doubling the number of extinction trials, enhances extinction retention in female rats, as all the animals used in these experiments were male. This issue is particularly important, given that it is well documented that the prevalence of anxiety disorders in humans is often as much as twice as high for females compared with males (Kessler et al, 2005), particularly in adolescence (Lewinsohn et al, 1998). Finally, it will be important to determine whether similar impairments in extinction retention are also observed in human adolescents. If they do, then such findings would have substantial implications for our understanding of treating anxiety disorders during this period of development. However, irrespective of the results of those future studies, the findings reported here clearly document that there is a marked impairment in extinction retention in adolescent rats.

\section{DISCLOSURE}

The authors declare no conflict of interest, direct or indirect, in submitting this work.

\section{REFERENCES}

Aupperle RL, Hale LR, Chamber RJ, Cain SE, Barth FX, Sharp SC et al (2009). An fMRI study examining effects of acute Dcycloserine during symptom provocation in spider phobia. CNS Spectr 14: 556-571.

Australian Code of Practice for the Care and Use of Animals for Scientific Purposes (2004) ( $7^{\text {th }}$ edn.). Australian Government Publishing Service: Canberra.

Baker JD, Azorlosa JL (1996). The NMDA antagonist MK-801 blocks the extinction of Pavlovian fear conditioning. Behav Neurosci 110: 618-620.

Bertotto ME, Bustos SG, Molina VA, Martijena ID (2006). Influence of ethanol withdrawal on fear memory: effect of d-cycloserine. Neuroscience 142: 979-990.

Blakemore SJ, Choudhury S (1999). Development of the adolescent brain: implications for executive function and social cognition. J Child Psychol Psychiatry 47: 296-312.

Bouton ME, Vurbic D, Woods AM (2008). D-cycloserine facilitates context-specific fear extinction learning. Neurobiol Learn Mem 90: $504-510$

Burgos-Robles A, Vidal-Gonzalez I, Santini E, Quirk GJ (2007). Consolidation of fear extinction requires NMDA receptordependent bursting in the ventromedial prefrontal cortex. Neuron 53: 871-880.

Choudhury S, Blakemore SJ, Charman T (2006). Social cognitive development during adolescence. Soc Cogn Affect Neurosci 1: $165-174$

Davis M, Ressler K, Rothbaum BO, Richardson R (2006). Effects of $\mathrm{D}$-cycloserine of extinction: translation from preclinical to clinical work. Biol Psychiatry 60: 369-375.

Falls WA, Miserendino MJD, Davis M (1992). Extinction of fearpotentiated startle: blockade by infusion of an NMDA antagonist into the amygdala. $J$ Neurosci 12: 854-863.
Fanselow MS (1980). Conditional and unconditional components of post-shock freezing. Integr Psychol Behav Sci 15: 1936-3567.

Geidd JN (2004). Structural magnetic resonance imaging of the adolescent brain. Ann N Y Acad Sci 1021: 77-85.

Gogtay N, Geidd JN, Lusk L, Hayashi KM, Greenstein D, Vaituzis AC et al (2004). Dynamic mapping of human cortical development during childhood through early adulthood. Proc Natl Acad Sci USA 101: 8174-8179.

Guastella AJ, Richardson R, Lovibond PF, Rapee RM, Gaston JE, Mitchell $\mathrm{P}$ et al (2008). A randomised controlled trial of Dcycloserine enhancement of exposure therapy for social anxiety disorder. Biol Psychiatry 63: 544-549.

Hefner K, Holmes A (2007). Ontogeny of fear-, anxiety-, and depression-related behaviour across adolescence in C57BL/6J Mice. Behav Brain Res 176: 210-215.

Herry C, Garcia R (2003). Behavioral and paired-pulse facilitation analyses of long-lasting depression at excitatory synapses in the medial prefrontal cortex in mice. Behav Brain Res 146: 89-96.

Hofmann SG (2007). Cognitive processes during fear acquisition and extinction in animals and humans: implications for exposure therapy of anxiety disorders. Clin Psychol Rev 28: 199-210.

Hofmann SG, Meuret AE, Smits JAJ, Simon NM, Pollack MH, Eisenmenger $\mathrm{K}$ et al (2006). Augmentation of exposure therapy with D-cycloserine for social anxiety disorder. Arch Gen Psychiatry 63: 298-304.

Hugues S, Chessel A, Lena I, Marsault R, Garcia R (2006). Prefrontal infusion of PD098059 immediately after fear extinction training blocks extinction-associated prefrontal synaptic plasticity and decreases prefrontal ERK2 phosphorylation. Synapse 60: 280-287.

Hugues S, Deschaux O, Garcia R (2004). Postextinction infusion of a mitogen-activated protein kinase inhibitor into the medial prefrontal cortex impairs memory of the extinction of conditioned fear. Learn Mem 11: 540-543.

Huttenlocher PR (1984). Synapse elimination and plasticity in developing human cerebral cortex. Am J Ment Defic 88: 488-496.

Kessler RC, Berglund P, Demler O, Jin R, Merikangas KR, Walters EE (2005). Lifetime prevalence and age-of-onset distributions of $D S M-I V$ disorders in the National Comorbidity Survey Replication. Arch Gen Psychiatry 62: 593-602.

Kim JH, Hamlin AS, Richardson R (2009). Fear extinction across development: the involvement of the medial prefrontal cortex as assessed by temporary inactivation and immunohistochemistry. J Neurosci 29: 10802-10808.

Kim JH, Li S, Richardson $\mathrm{R}$ (in press). Immunohistochemical analyses of long-term extinction of conditioned fear in adolescent rats. Cereb Cortex.

Kim JH, Richardson R (2007a). A developmental dissociation in reinstatement of an extinguished fear response in rats. Neurobiol Learn Mem 88: 48-57.

Kim JH, Richardson R (2007b). A developmental dissociation of context and GABA effects on extinguished fear in rats. Behav Neurosci 121: 131-139.

Kim JH, Richardson R (2010). New findings on extinction of conditioned fear early in development: theoretical and clinical implications. Biol Psychiatry 67: 297-303.

Langton JM, Kim JH, Nicholas J, Richardon R (2007). The effect of the NMDA receptor antagonist MK-801 on the acquisition and extinction of learned fear in the developing rat. Learn Mem 14: 665-668.

Langton JM, Richardson R (2008). D-cycloserine facilitates extinction the first time but not the second time: an examination of the role of NMDA across the course of repeated extinction sessions. Neuropsychopharmacology 33: 3096-3102.

Larson R, Csikszentmihalyi M, Graef R (1980). Mood variability and the psychosocial adjustment of adolescents. J Youth Adolesc 9: 469-490. 
Lebron K, Milad MR, Quirk GJ (2004). Delayed recall of fear extinction in rats with lesions of ventral medial prefrontal cortex. Learn Mem 11: 544-548.

Ledgerwood L, Richardson R, Cranney J (2003). Effects of D-cycloserine on extinction of conditioned freezing. Behav Neurosci 117: 341-349.

Ledgerwood L, Richardson R, Cranney J (2004). D-Cycloserine and the facilitation of extinction of conditioned fear: consequences for reinstatement. Behav Neurosci 118: 505-513.

Ledgerwood L, Richardson R, Cranney J (2005). D-Cycloserine facilitates extinction of learned fear: effects on reacquisition and generalized extinction. Biol Psychiatry 57: 841-847.

Lewinsohn PM, Gotlib IH, Lewinsohn M, Seeley JR, Allen NB (1998). Gender differences in anxiety disorders and anxiety symptoms in adolescents. J Abnorm Psychol 107: 109-117.

Milad MR, Quinn BT, Pitman RK, Orr SP, Fischl B, Rauch SL (2005). Thickness of ventromedial prefrontal cortex in humans is correlated with extinction memory. Proc Natl Acad Sci USA 102: 10706-10711.

Milad MR, Quirk GJ (2002). Neurons in medial prefrontal cortex signal memory for fear extinction. Nature 420: 70-74.

Milad MR, Wright CI, Orr SP, Pitman RK, Quirk GJ, Rauch SL (2007). Recall of fear extinction in humans activates the ventromedial prefrontal cortex and hippocampus in concert. Biol Psychiatry 62: 446-454.

Monaghan DT, Cotman CW (1985). Distribution of N-methyl-Dasparate-sensitive $\mathrm{L}-\left[{ }^{3} \mathrm{H}\right]$ glutamate binding sites in rat brain. J Neurosci 5: 2909-2919.

Mrzljak L, Uylings HBM, Van Eden CG, Judas M (1990). Neuronal development in human prefrontal cortex in prenatal and postnatal stages. Prog Brain Res 85: 185-222.

Myers KM, Davis M (2002). Behavioral and neural analysis of extinction. Neuron 36: 567-584.

Norberg MM, Krystal JH, Tolin DF (2008). A meta-analysis of D-cycloserine and the facilitation of fear extinction and exposure therapy. Biol Psychiatry 63: 1118-1126.

Phelps EA, Delgado ML, Nearing KI, LeDoux JE (2004). Extinction learning in humans: role of the amygdala and vmPFC. Neuron 43: 897-905.
Quirk GJ (2002). Memory for extinction of conditioned fear is long-lasting and persists following spontaneous recovery. Learn Mem 9: 402-407.

Quirk GJ, Russo GK, Barron JL, Lebron K (2000). The role of the ventromedial prefrontal cortex in the recovery of extinguished fear. J Neurosci 20: 6225-6231.

Ressler KJ, Rothbaum BO, Tannenbaum L, Anderson P, Graap K, Zimand $\mathrm{E}$ et al (2004). Cognitive enhancers as adjuncts to psychotherapy: use of $\mathrm{D}$-cycloserine in phobic individuals to facilitate extinction of fear. Prog Brain Res 61: 1136-1144.

Santini E, Quirk GJ, Porter JT (2008). Fear conditioning and extinction differentially modify the intrinsic excitability of infralimbic neurons. J Neurosci 28: 4028-4036.

Shaw P, Kabani NJ, Lerch JP, Eckstrand K, Lenroot R, Gogtay N et al (2008). Neurodevelopmental trajectories of the human cerebral cortex. J Neurosci 28: 3586-3594.

Sowell ER, Thompson PM, Holmes CJ, Jernigan TL, Toga AW (1999). In vivo evidence for post-adolescent brain maturation in frontal and striatal regions. Nat Neurosci 2: 859-861.

Storch EA, Merlo LJ, Bengtson M, Murphy TK, Lewis MH, Yang MC et al (2007). D-cycloserine does not enhance exposureresponse prevention therapy in obsessive-compulsive disorder. Int Clin Psychopharmacol 22: 230-237.

Van Eden CG, Kros JM, Uylings HBM (1990). The development of the rat prefrontal cortex: its size and development of connections with thalamus, spinal cord and other cortical areas. Prog Brain Res 85: 169-183.

Walker DL, Ressler KJ, Lu K, Davis M (2002). Facilitation of conditioned fear extinction by systemic administration or intraamygdala infusions of D-cycloserine as assessed with fear potentiated startle in rats. I Neurosci 22: 2343-2351.

Wilhelm S, Buhlmann U, Tolin DF, Meunier SA, Pearlson GD, Reese HE et al (2008). Augmentation of behavior therapy with D-cycloserine for obsessive-compulsive disorder. Am J Psychiatry 165: 335-341.

Yap CSL, Richardson R (2007). Extinction in the developing Rat: an examination of renewal effects. Dev Psychobiol 49: 565-575. 